\title{
TÉCNICAS TRADICIONALES DE INFORMACIÓN GEOGRÁFICA (TTIG) EN EL ANÁLISIS DE LAS TRANSFORMACIONES RECIENTES DEL RIU MILLARS (CASTELLÓ, ESPAÑA)
}

\author{
Juan Antonio Marco Molina* \\ MEDSPAI (Grupo de Investigación sobre Medio, Sociedad y Paisaje), CIBIO (Instituto \\ Universitario de la Biodiversidad), Departamento de Análisis Geográfico Regional y \\ Geografía Física y Laboratorio de Biogeografía (Instituto Interuniversitario de Geografía), \\ Universidad de Alicante
}

\section{RESUMEN}

Con la referencia inicial a la acusada transformación del paisaje vegetal, se analizan los cambios recientes que han afectado al lecho fluvial del Riu Millars en su tramo más bajo. Se centra el foco en las transformaciones antopogénicas, cuyas evidencias o constataciones se han llevado a cabo mediante la utilización de lo que se han denominado Técnicas Tradicionales de Información Geográfica (TTIG), tales como la fotointerpretación diacrónica y retrospectiva, trabajos de campo, encuestas, así como recopilación toponímica y de documentación histórica. No obstante, los resultados derivados de estas técnicas tradicionales han sido tratados y presentados a partir del uso de las TIG más recientes. Todo ello en el contexto de cambio de mentalidad de la sociedad respecto de los sistemas fluviales o del medio natural, en general; es decir, desde la perspectiva de cómo se perciben y valoran, por parte de la sociedad, los medios riparios.

Palabras clave: evolución del paisaje, dinámicas de cambio, medios fluviales, ocupación de tierras, percepción, mentalidad y medio ambiente

\footnotetext{
*ja.marco@ua.es
} 


\begin{abstract}
Geographic Information Traditional Techniques (GITT) in the analysis of recent changes of Millars River (Castelló, Spain)
\end{abstract}

With the initial transformation of the defendant reference vegetable landscape, the recent changes that have affected the Millars river bed at its lowest stage are analyzed. Focus on the human transformations, whose evidence or verifications have been carried out by using what are called Geographic Information Traditional Techniques (TTIG), such as photo interpretation and diachronic retrospective, field works, interviews, collection of toponymic and historical documentation. However, the results derived from these traditional techniques have been processed and presented through the use of the latest GIT. All this in the context of change in mentality of the society about river systems or the environment in general; that is, from the perspective of how society perceives and values riparian environments.

Keywords: landscape evolution, dynamics of change, fluvial environments, land occupation, perception, mentality and environment

\title{
INTRODUCCIÓN
}

Con este título se encabeza un trabajo cuyo principal objetivo no es otro que el de esbozar un registro de los principales cambios que ha experimentado el Riu Millars en su tramo más bajo en relación con la manera en que la sociedad ha percibido y valorado el sistema fluvial del Riu Millars, en especial, en su tramo más bajo; es decir, el comprendido entre la confluencia con la Rambla de la Viuda y la desembocadura. Para ello se han utilizado algunas de las técnicas que, de manera genérica, se podrían denominar Técnicas Tradicionales de Información Geográfica (TTIG). Es decir, a partir de fuentes como la documentación histórica, fotografía aérea de diversas épocas, el trabajo de campo, la cartografía histórica o la oficial, se ha procedido, por un lado, a la interpretación de los aspectos geográficos contenidos en la documentación histórica; a continuación, se han desarrollado labores de fotointerpretación de fotogramas y ortofotos correspondientes a distintas fechas, a partir de la cual, se ha aplicado un análisis espacial comparado de carácter diacrónico utilizando, ya, las técnicas de información geográfica (TIG) que se han incorporado al quehacer geográfico más recientemente.

$\mathrm{Si}$ se tomase el paisaje vegetal que presenta el río desde su entrada en la plana hasta su salida al mar como elemento de referencia, bastaría con inventariar las unidades de vegetación presentes a lo largo del río y, a tenor de su significado en la dinámica en las series de vegetación, extraer como diagnóstico, el de una acusada transformación respecto de los modelos teóricos asignados a estos lechos fluviales. Sin embargo, este planteamiento adolecería de excesivo 
mecanicismo y simplismo. El esquema teórico de distribución de la vegetación de ribera indica que ésta es un mosaico que se organiza en franjas paralelas al curso fluvial, siguiendo un vector de mayor a menor humedad superficial y edáfica, desde la misma orilla hacia las márgenes. De este modo, en las orillas se establecería una vegetación acuática de carácter herbáceo en la que destacarían especies como la mansiega o segamà (Claudium mariscus) y la enea o boga (Typha sp. pl.). A continuación, y en los canturrales del propio lecho, seguirían saucedas de porte arbustivo, representadas, en este ámbito, por los sargares (Salix eleagnos). Después estarían las arboledas compuestas por chopos o xops (Populus nigra) y álamos blancos o àlbers (Populus alba); mientras que en los sectores más alejados del río y del nivel freático aparecerían las olmedas (Ulmus minor). De este modelo y de sus representantes queda bien poco. Sólo hay fragmentos muy localizados y dispersos, de manera que el diagnóstico sería en una primera aproximación, muy negativo. En especial, si nos referimos al conjunto de la Plana, donde se pueden citar topónimos como los de el Bosc, l'Arbreda, el Xopar o l'Illa del Sargar, todos ellos en Almassora, que han quedado fosilizados y que son la memoria histórica de un paisaje hoy profundamente transformado.

Esta conclusión es, a la vez, acelerada y relativa. Acelerada porque el razonamiento peca de un acusado mecanicismo ecológico. Y relativa, porque calificar el estado de la vegetación sin una perspectiva diacrónica puede resultar engañosa de su potencial evolutivo. En cualquier caso, no se debe olvidar que el paisaje fluvial es, en gran medida, lo que la sociedad ha pretendido y pretende que sea.

\section{PERCEPCIÓN Y VALORACIÓN TRADICIONAL DEL MEDIO}

Se parte de la premisa ineludible de que tanto el río como la plana aluvial por él generada son, sin excepción, espacios o, si se prefiere, paisajes humanizados, cuando no, intensamente humanizados. Así, se quiere subrayar que, ni esta dilatada plana aluvial, ni el río propiamente dicho se pueden calificar como algo natural, aunque en este último, haya sectores que gocen de una cierta naturalidad que deriva de la percepción y valoración que del medio físico se ha hecho en época muy reciente.

Pero al hablar de la manera más reciente de percibir el medio, se hace referencia a que en poco más de un siglo se pueden señalar hasta tres modos distintos que, a su vez, expresan los cambios que han experimentado las relaciones entre sociedad y medio (García, 1994 y 1995) o, en este caso concreto, entre sociedad y río.

-Aunque podríamos remontarnos mucho más atrás, conviene recordar que desde las últimas décadas del siglo xIx hasta el primer cuarto del siglo xx, se alzaprimó el medio o la naturaleza, de tal modo que los seres vivos, incluido el 
hombre, no tienen más remedio que plegarse a los dictados de las leyes de la Naturaleza. Es lo que se ha denominado determinismo geográfico.

-A medida que progresaron los conocimientos se pudo apreciar que lo natural no siempre era tan natural: el espacio había sido transformado, era un espacio habitado, en el que lo natural había sido sustituido por lo antropogénico; se retomó, entonces, la expresión paisaje, para referirse a un espacio humanizado o transformado. En todas las ciencias relacionadas con la naturaleza fue imprescindible el estudio de la modificación introducida por el hombre. Mentalidad que entre los años 20 y 60 caló por completo en la cultura general y, en su desarrollo, se pasó del hombre transformador al hombre dominador de la Naturaleza, la cual fue desestimada.

-Por esta vía de sobrevalorar la actuación del hombre y subestimar la acción de la Naturaleza pronto se llegó a considerar al hombre como perturbador, hasta tal punto que ha puesto en peligro su supervivencia. A partir de los años 60, en EEUU, el estudio del medio, environment, es sinónimo del estudio del deterioro de la Naturaleza provocado por la actividad humana. Se genera así una nueva mentalidad y manera de percibir el medio, el cual es preciso conservar y proteger.

En el contexto de cada una de estas mentalidades, a tenor de las necesidades y de los niveles tecnológicos de la sociedad, se establecen unas relaciones concretas entre sociedad y río. Relaciones basadas en la percepción y valoración que se hace de estos elementos del medio físico y que siempre han tenido un carácter dual, ya que se toman en consideración tanto las ventajas como los inconvenientes inherentes a los mismos.

Riu Millars y Rambla de la Viuda han conformado un imponente abanico aluvial hendido en su bisectriz por el primero de ellos y terminado en un delta. Constituyen, en conjunto, un ejemplo de los denominados por Segura (1990), conos progradantes. Esta infraestructura o soporte ha merecido una valoración muy positiva desde antiguo, ya que dicho abanico, como sección de de un cono, determina una convexidad en su parte central, de tal modo que resulta relativamente «fácil» derivar las aguas desde el cauce hacia las tierras aledañas. L'Assut de Vila Real, el de Almassora y el de Borriana, así como la red divergente de acequias son los elementos básicos en la articulación de este territorio y en la construcción del paisaje agrario de la Plana. A partir de la derivación de aguas en el azud, tras un primer tramo paralelo al río hasta alcanzar el nivel superior del abanico, basta con trazar una acequia siguiendo una curva de nivel, como para conducir las aguas a prácticamente todo el término de Vila-real. Más clara, si cabe, es la relación entre la morfología del abanico y el trazado de la red de acequias de Borriana y, sobre todo, de Almassora. En ambos casos, una acequia, en paralelo al cauce del río, es decir, por el sector que domina al resto del abanico, facilita su derivación sucesiva de forma más o menos radial y divergente 
hacia los extremos del mismo. Circunstancia que conviene retener, puesto que, en ambos casos, dichas acequias longitudinales es muy probable que, en otro tiempo, marcasen el límite del propio río.

Estas ventajas que ofrece el medio físico, fundamentalmente identificadas con el río, son suficientes como para aceptar inconvenientes o amenazas del mismo como las furiosas avenidas y el papel de barrera de las comunicaciones. La situación descrita correspondería, como etapa de finalización de algunos proyectos, con las postrimerías del siglo XvIII. Cavanilles fue testigo de excepción de la culminación de un proceso más o menos continuado en el tiempo de ampliación de la superficie agraria y, sobre todo, del regadío. Proceso analizado por Domingo (1983) para este sector y por Giménez (2008a) para el ámbito valenciano. Hasta que no llegaron avances técnicos importantes, la única forma de incrementar los rendimientos se basaba en la ampliación del ager o la transformación al regadío. Sobre este último, si bien hay noticias de riegos de época islámica, autores como Mateu (1989) subrayan la importancia de la Reconquista y repoblación de estas tierras, a partir del siglo XIII, en la formación del sistema de riegos del Baix Millars. Sistema que, como avanzamos, debía estar casi completamente desarrollado en tiempos de los viajes del ilustrado valenciano. No escatima elogios para referirse a las producciones de la Plana y a los avances que experimentó, especialmente en aquella centuria, la población de cuatro lugares [Almassora, Borriana, Castelló y Vila-real] tan inmediatos y con tantos vecinos (Cavanilles, 1795: 100). En la descripción de Almassora, a pesar de exclamar, cuando enumera sus producciones, ;Qué bien pagados se ven aqui los sudores de los hombres!, se infiere que la saturación territorial es un hecho, ya que parte de sus vecinos salen a cultivar las heredades que tienen en los términos colindantes, sobre todo, en Borriana (Cavanilles, 1795: 106). Ni Borriana, ni Vilareal, van a la zaga. Cuando comienza la descripción del primero de ellos, los notables aumentos de población, así como de la superficie cultivada, que según sus cálculos se ha cuadruplicado, señala que el rio Milláres es la verdadera causa de estos fenómenos admirables, del qual toman los de Borriana tantas aguas, que han convertido en huertas todo el término (Cavanilles, 1795: 107); situación similar a la descrita para Vila-real, donde destaca que uno de los factores que ha facilitado los aumentos de este pueblo es la abundancia de aguas, hasta el punto de tener cultivado todo su término (Cavanilles, 1795: 108). No debe extrañar, pues, que se registren en esta época intentos de colonización y fundación de nuevas poblaciones, como la de Benadressa (término municipal de Castelló), analizada por Giménez (2008b).

Es evidente, pues, que la prosperidad de estos pueblos y, en general, de la Plana deriva de las ventajas que ofrece el medio físico y, más concretamente, el río; percepción que expresa con rotundidad Cavanilles (1795: 100) cuando afirma que el Milláres es la fuente de la abundancia. Pero no por ello hay que 
entender que en esa valoración no se han considerado las desventajas. Creo que no es casual que ninguna de las tres villas se asome al Millars. Únicamente el antiguo emplazamiento-castillo de Almassora podía verse afectado por las furiosas avenidas del río. En ese sentido, casi se podría afirmar que la relación entre las ciudades y el río estaba basada en la integración y que tenía un acusado carácter horizontal. Tanto debía ser así, que este conocimiento del medio y del funcionamiento del río, provocó dudas y contestación cuando Ribelles, arquitecto valenciano, acometió la construcción del puente del camino real de Barcelona, aguas abajo de la confluencia entre Millars y Rambla de la Viuda. Dudas que se disiparon cuando resistió, sobradamente, la mayor riada que se ha conocido (Cavanilles, 1795: 109). No concreta la fecha de dicho episodio $\mathrm{y}$, aunque visitó este sector durante la segunda mitad del mes de mayo de 1793 (Mateu, 1995: 36), a falta de más comprobaciones, no sería extraño que se tratase de la riada de 15 de octubre de 1793, ya que según Mateu (1995: 44), tras su regreso a Madrid, mantuvo una intensísima actividad epistolar con los corresponsales de los pueblos que aparecerían en la publicación de 1795. Es posible que tuviese noticias de aquella riada por ese medio. En cualquier caso, si se ha traído a colación, es porque se han localizado dos planos realizados el 24 de octubre de ese mismo año por Fray Joaquín del Niño Jesús (Archivo Histórico Nacional, Consejos, Legajo 37.387) en los que el objeto es el mismo, reparar los daños en las infraestructuras de riego y de comunicaciones que causó la susodicha avenida del Millars y cuencas vertientes vecinas en el día de Santa Teresa. En uno de ellos se trata del puente-acueducto de la Sèquia de Castelló cuando atraviesa el Barranc d'Almassora. Este proyecto tiene su continuación en otro posterior, firmado por Cristóbal Sales, en el que los detalles de las secciones de dicho puente son un auténtico alarde acerca del conocimiento que se tenía, en aquella época, del comportamiento de este barranco y que queda reflejado con la representación de los calados alcanzados durante avenidas regulares y crecientes de las mayores avenidas (figura 1), planteamiento idéntico al utilizado por este mismo autor en el proyecto de los puentes del Calvari y de la Enramada sobre el Barranc de la Sequiassa, también en término de Castelló ${ }^{2}$. Argumentos que, en definitiva, denotan signos de la aludida integración entre sociedad y medio físico.

Sin embargo, esta integración es compatible con una intensa humanización, cuya plasmación fue un paisaje agrario tan característico como el de la Plana, pero que, no sólo afectó al abanico aluvial, sino que también tuvo gran

2. Suponemos que es continuación del otro de los proyectos citados de Fray Joaquín del Niño Jesús, puesto la coincidencia de topónimos, salvo en el caso del Barranc de la Sequiassa, es total. Esta documentación ha sido amablemente cedida por Pablo Giménez Font. Archivo Histórico Nacional (AHN), Consejos, Legajo 37.387. 


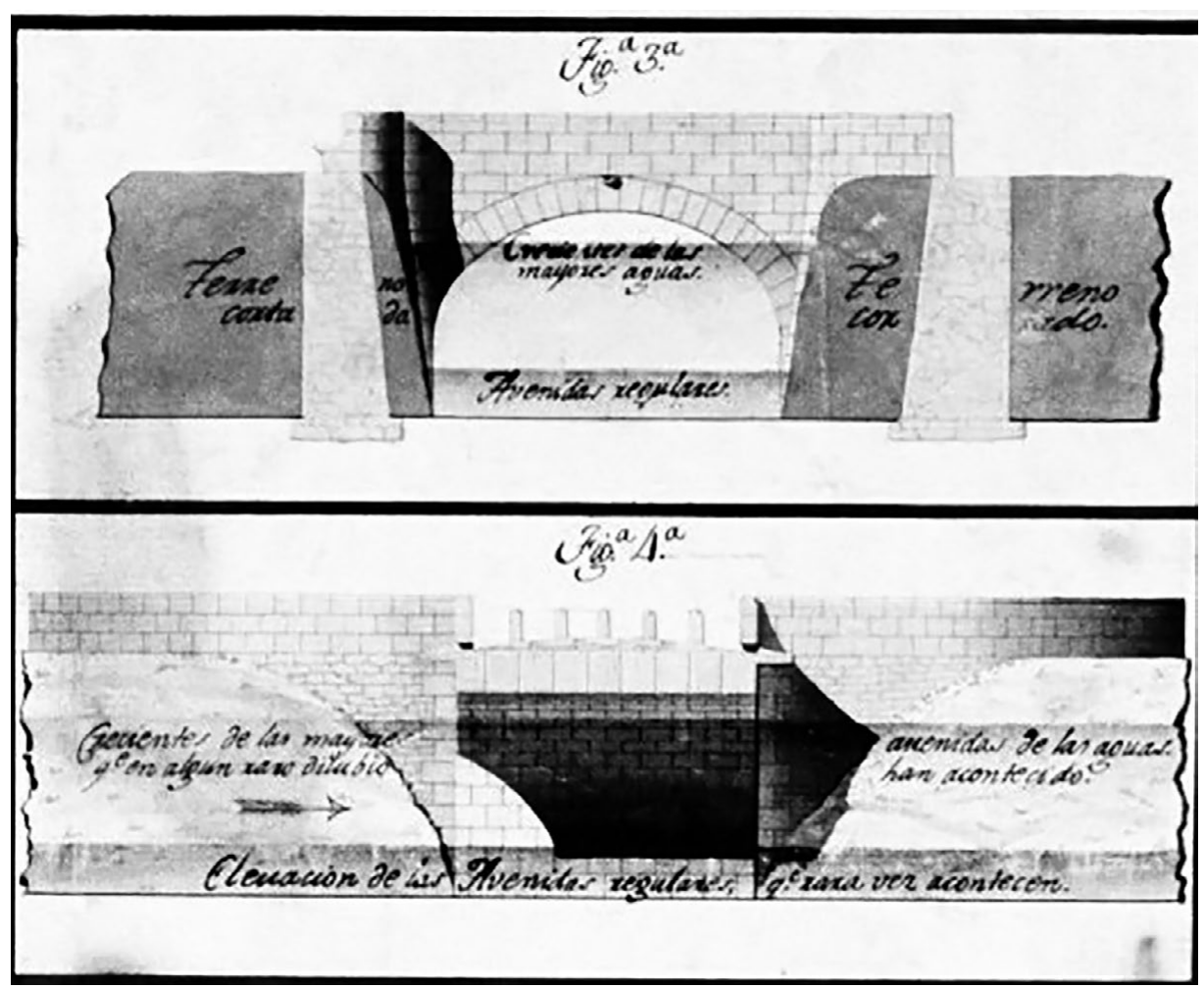

Figura 1. Detalle del plano de Cristóbal Sales (1793) en el que se expresan los calados de las avenidas regulares y de las mayores. Archivo Histórico Nacional (AHN), Consejos, Legajo 37.387 .

trascendencia en el resto de ecótopos. El territorio, con claros síntomas de saturación, se aprovechaba de forma íntegra. En Almassora ya se ha apuntado la acusada falta de terrazgo y que en Borriana y Vila-real todo son huertas. Otra de las carencias destacadas por Cavanilles (1795: 106, 107 y 109) para las tres villas es la del estiércol y que, en Burriana, acuden á médios ruinosos para conseguirlo, mientras que, en Almassora, único municipio con alguna porción de secano, palian dicha carencia traspasando tierras desde los campos de secano a las huertas. Tanto se ha extendido la agricultura que no hay baldíos de los que conseguir leña, especialmente en Borriana, donde sólo queda al margen del cultivo el Serradal (terreno arenoso junto al mar). Es lícito pensar que, el río y sus márgenes, integrarían una franja libre de cultivo, aunque no exenta de otros aprovechamientos, a parte de los hídricos. En efecto, el lecho y las márgenes debieron estar frecuentados por los ganados. Condición de las zonas húmedas, de sobra conocida, es la de constituir ecosistemas con las tasas más elevadas de 
producción de biomasa. Muchas de las formaciones de ribera se componen por especies vegetales de ciclo vegetativo anual. En definitiva, características que abonan la idea de que la vegetación ripícola ha podido estar aprovechada de manera muy intensa.

Productos como los derivados de la enea o boga (Typha sp. pl.), del carrizo o carrís (Phragmites australis) y, sobre todo, de la caña (Arundo donax), desempeñaban un papel fundamental en la fabricación de muebles y enseres domésticos, en la elaboración de útiles y accesorios para la agricultura o como componentes básicos en la construcción de viviendas; sin descartar que, en ocasiones, tanto la materia prima como las manufacturas obtenidas, llegaron a constituir importantes complementos en las rentas familiares. No puedo resistir la tentación de traer a colación una nueva cita de Cavanilles (1795: 105) con la que «ilustrar» los comentarios previos, ya que, tras resaltar la abundante producción de algarrobas de Castelló, escribe que es un auténtico espectáculo ver la multitud de individuos de ambos sexôs y de todas las edades que salen á recogerlas $\mathrm{y}$, lo que es más importante, que se ven muchos armados de largas cañas de 16 á 20 palmos, que conservan parte de la raiz en arco para sacudir y hacer caer las algarrobas...

A tenor de las circunstancias que se acaban de apuntar, quedarán pocos rescoldos que puedan avivar alguna duda acerca de la intensa humanización de la que fue objeto este territorio en su totalidad. Es más, cabe preguntarse por el aspecto que tendrían el lecho y la vegetación de ribera en aquellos momentos. El escaso tiempo del que se ha dispuesto y los pocos documentos de la época consultados no han sido de gran ayuda. Cavanilles, obnubilado por las producciones de estas tierras, es, por el contrario, silente al respecto. No hay más remedio que callar o plantear alguna hipótesis; y, por no emular al susodicho, se ha optado por lo segundo.

Se parte de la premisa de que la estructura y funcionamiento del paisaje de la Plana, hasta fechas muy recientes, se han caracterizado por una acusada inercia, de tal manera que, hasta la década de los años sesenta del siglo xx, se han mantenido sus trazas fundamentales. Aceptado este principio, al menos al respecto del lecho del río, los fotogramas aéreos correspondientes a la llamada «Serie B del vuelo americano» de 1956, adquieren gran relevancia. A pesar de la escala de los mismos (aproximadamente 1:33.000), a pocos pasaría desapercibida la franja oblicua de coloración blanca que se corresponde con el lecho del Millars en su tramo más bajo (figura 3). Coloración que, como se indicó en un estudio semejante sobre el Riu Algar (Marco, Matarredona y Padilla, 1998), se debe al alto valor del albedo propio de un lecho sembrado de cantos y prácticamente desprovisto de vegetación. Evidentemente, se diferencian sectores muy blancos correspondientes a los canales de circulación en episodios de avenida de diversa intensidad y sectores, más o menos fusiformes, con un leve matiz 


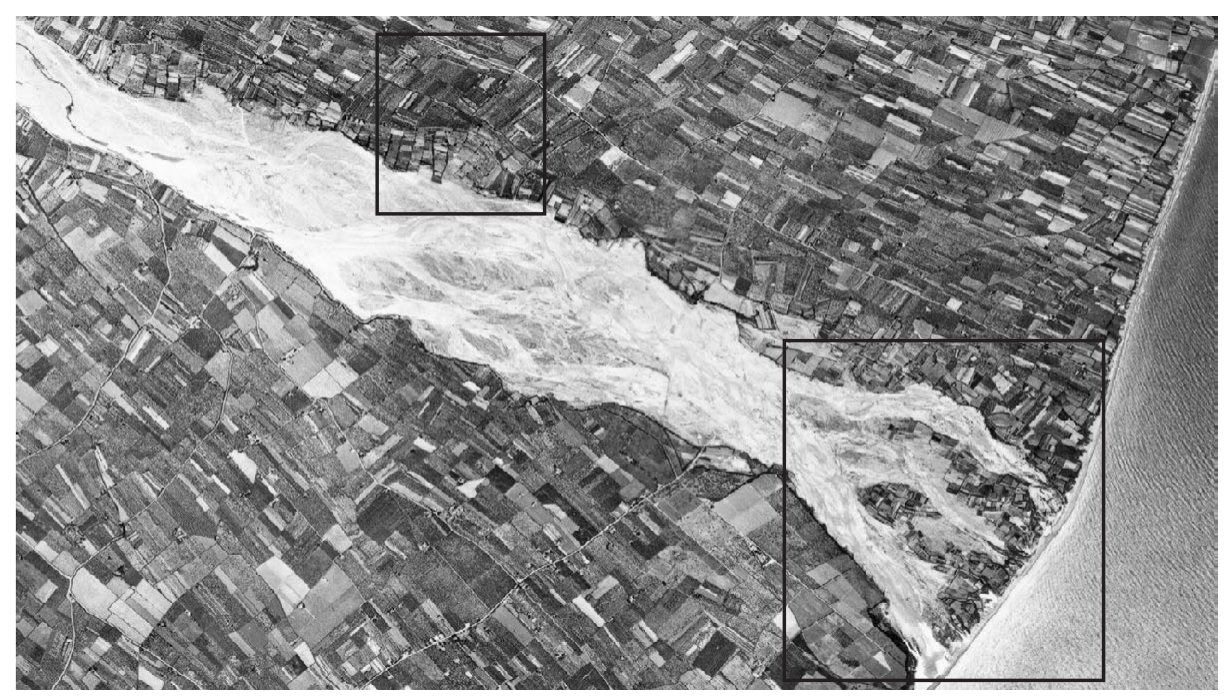

Figura 2. Fragmento de fotograma aéreo del vuelo americano de 1956. En rojo, localización de los detalles de la figura 4.

grisáceo, discernibles como barras de cantos con una incipiente colonización vegetal. Pero, en conjunto el balance es claramente favorable al blanco, es decir, a la práctica ausencia de vegetación.

Éste es otro hecho a tener en cuenta, puesto que cuando se analiza la vegetación actual de ribera el contraste es brutal, sobre todo, por la elevada densidad que se alcanza en algunos sectores. Es, por tanto, una referencia que merece una reflexión, porque lo actual se percibe y se conceptúa como etapas de sustitución de lo primitivo. Afirmación que, con frecuencia, adquiere un sentido de regresión, cuando, en realidad, visto lo visto, se debería contemplar como prueba innegable de una intensa y prometedora recuperación.

\section{LOS LÍMITES DEL LECHO FLUVIAL COMO EXPRESIÓN DE SU ARTIFICIALIZACIÓN}

Una vez se ha señalado que la evolución reciente de la vegetación de ribera ha sido positiva, otros elementos de la imagen aportan información complementaria que permiten afirmar que dicha regeneración se ha producido, incluso, a pesar de que no han cesado las alteraciones del ambiente ripario. Más bien al contrario, la comparación del aspecto del lecho en el año indicado con una fotografía aérea más reciente revela modificaciones importantes no sólo de la morfología del mismo, sino de los límites fisiográficos del lecho en uno y otro momento. Es más, casi se puede afirmar con rotundidad, que los cambios producidos en este tramo bajo del río en apenas cincuenta años, han sido los más 


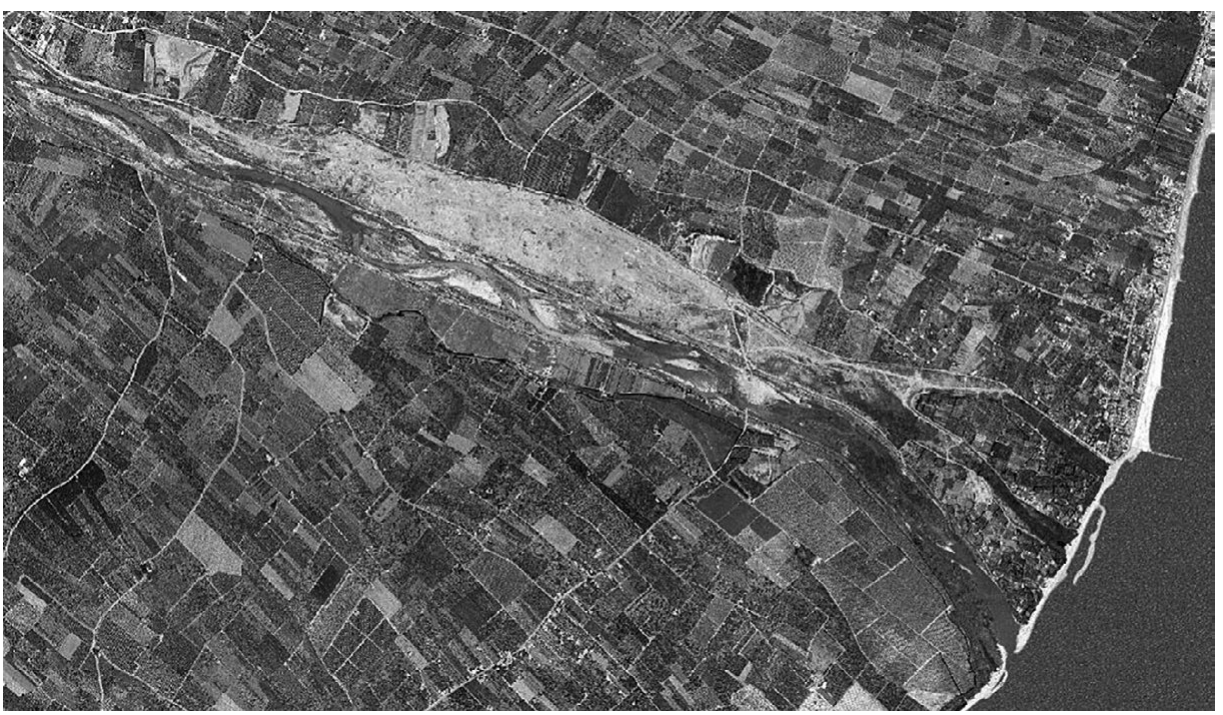

Figura 3. Fragmento de ortofoto del Institut Cartogràfic Valencià de 2002.

drásticos, por cuanto que, en conjunto, suponen una considerable reducción de la superficie ocupada por el río en sentido estricto.

La comparación se ha realizado entre la fotografía aérea de 1956 y la ortofoto del Institut Cartogràfic Valencià (ICV) de 2002 (figura 3). Los resultados se han considerado satisfactorios, como aproximación a la cuestión, aunque serían más ricos en matices y precisos de contar con todas las imágenes aéreas de fechas intermedias de las que se dispone (1978, 1984, 1985, 1993 y 1998) o, incluso, la recientemente aflorada «Serie A del vuelo americano» (1946-47). Por razones obvias, para la representación cartográfica se ha utilizado como soporte la ortofoto más reciente, de manera que se ha realizado una fotointerpretación retrospectiva que ha sido posible gracias a la integración de ambas imágenes en un sistema de información geográfica embrionario que únicamente perseguía la elaboración de una capa de información sobre la evolución de los límites del lecho del Riu Millars con la que poder cuantificar los datos espaciales y obtener una salida cartográfica específica.

En la fotografía más antigua, el límite fisiográfico del lecho viene marcado por el contacto entre el material aluvial que lo tapiza y las parcelas de cultivo. A simple vista, hay sectores tanto en la margen septentrional -la de Almassora-, como en la meridional -la de Borriana - en los que está claro que los terrenos cultivados han avanzado en detrimento del lecho fluvial y que, por tanto, serían terrenos ganados para el cultivo entre 1956 y 2002. 
Esta sería, en buena lógica, la primera de las transformaciones a anotar entre las fechas de ambos vuelos. Sin embargo, un análisis detallado revela una curiosa, a la par que expresiva morfología del parcelario de la margen septentrional. Casi de forma paralela al trazado de la acequia que discurre en sentido longitudinal a lo largo del abanico, hay una franja en la que es evidente la disminución del tamaño de las parcelas. Por lo común son de forma rectangular, pero de manera que sus lados mayores son el septentrional y el meridional. Varias de estas parcelas, siguiendo el eje indicado, es decir, norte-sur, terminan por ocupar el espacio comprendido entre la acequia aludida y el lecho del río propiamente dicho. Disposición y morfología que se repite con bastante frecuencia (figura 5). Además, no faltan ejemplos en los que las parcelas más próximas al Millars sólo se reconocen por los linderos. Da la impresión de que falta rellenar un perímetro previamente delimitado. Circunstancias que, en conjunto, indican que la interpretación más verosímil conduciría a que las parcelas descritas en último lugar se corresponden con una de las fases del mecanismo seguido para ganar terreno al lecho del río. De ese modo, los lados meridionales de cada una de las microparcelas dispuestas en sentido transversal al eje del río son, en realidad, las sucesivas posiciones del frente de avance de la tierra agrícola respecto del lecho fluvial. Idéntico significado se ha otorgada a las parcelas que se localizan en el delta del Millars coincidiendo con las barras-islas de aluvión -hoy Alters- que individualizan las cuatro golas reconocibles en los fotogramas de 1956 (Figura 5). Con el ánimo de corroborar esta hipótesis, se procedío a aplicar otra de las técnicas que tradicionalmente se han desarrollado durante los trabajos de campo: la encuesta. No resultó sencillo, pues las edificaciones que hoy en día ocupan los
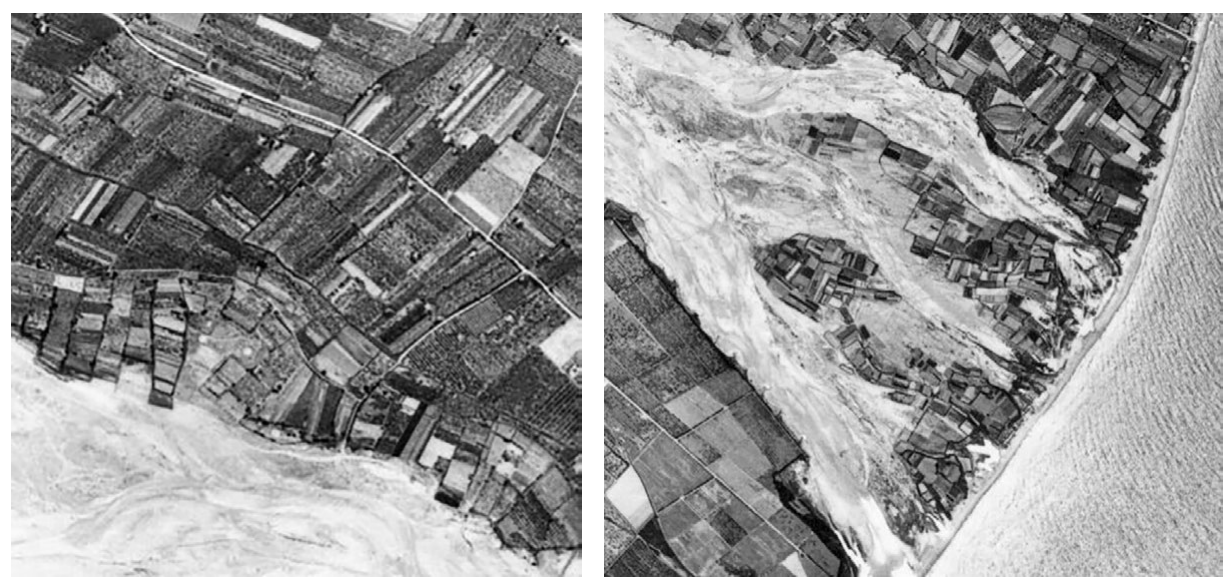

Figura 4. Detalles de la fotografía aérea de 1956. A la izquierda, límite sinuoso entre dos morfologías parcelarias contrastadas interpretado como antiguo lecho ganado para el cultivo. A la derecha, delta del Millars en el que se reconocen hasta cuatro golas, donde ya es evidente la colonización incipiente de los denominados Alters. 
EVOLUCION DE LOS LMITES DE RIU MILLARS

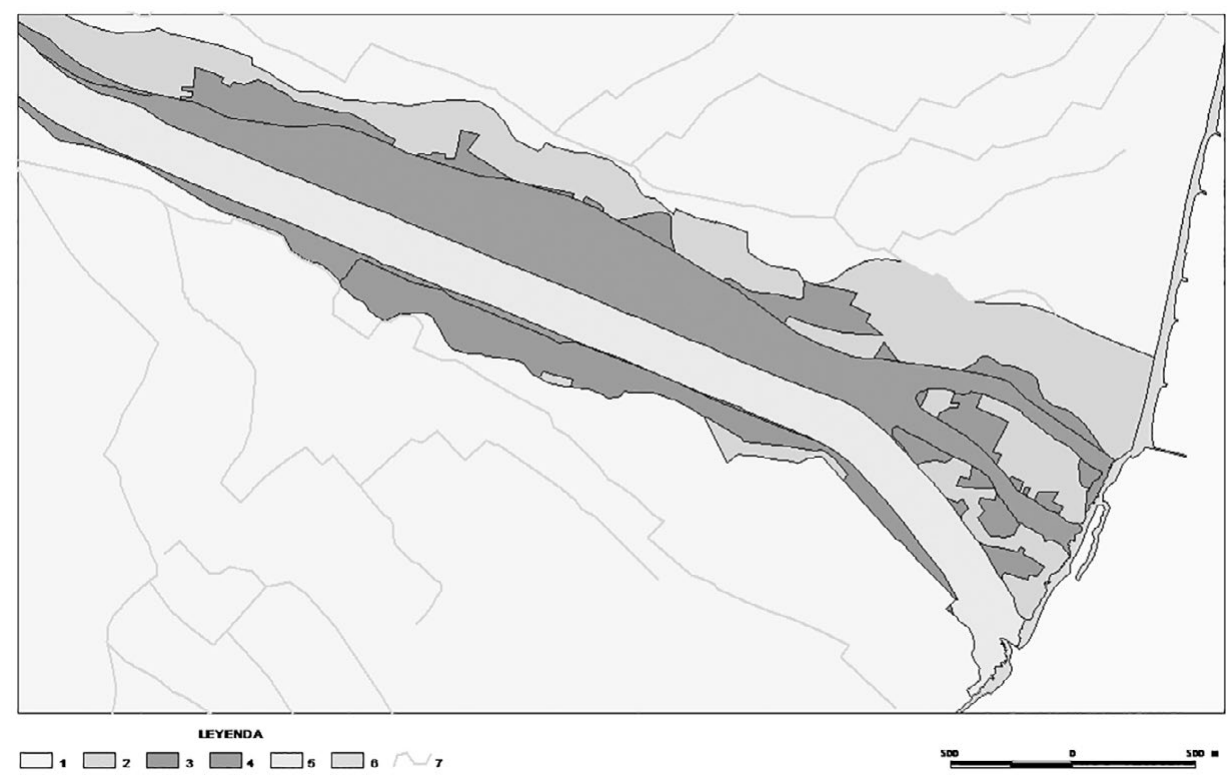

Figura 5. Artificialización reciente del lecho del Riu Millars a partir de la fotografía de 1956 y ortofoto ICV de 2002. 1. Espacio agrícola tradicional. 2. Espacios agrícolas supuestamente ganados al río hacia mediados del siglo XX. 3. Espacios agrícolas ganados al río entre 1956 y 2002. 4. Espacios marginados por el encauzamiento del lecho. 5. Lecho actual encauzado. 6. Cordón costero de gravas. 7. Red de acequias de Borriana y Almassora.

alters entre golas, se encuentran en situación irregular, fuera de ordenación. No obstante, la confirmación del proceso de bonificación descrito, fue corroborado y relatado con detalle por un vecino de Almassora, Lino Martínez Cantavella; el cual sitúa temporalmente, las primeras bonificaciones, inmediatamente antes de la Guerra Civil, mientras que señala la década comprendida entre 1950 y 1960, como la de máxima intensidad de creación de terrazgo a costa del lecho.

Como se ha podido apreciar, este proceso es, al menos, coetáneo o anterior a la fecha de las fotografías y se han identificado como espacios agrícolas ganados al lecho hacia mediados del siglo xx (Figura 5). Este proceso no ha sido, en modo alguno simétrico en ambas márgenes; de hecho, casi se podría decir que es propio de la margen septentrional, la que corresponde a Almassora. Localidad de la que conviene recordar que ya en tiempos de Cavanilles la saturación territorial era un problema más acusado que en los pueblos vecinos y, aunque no pase de un detalle sugerente, también es en Almassora donde se remediaba la falta de estiércol mediante el acarreo de tierra desde el secano a las huertas. Si 

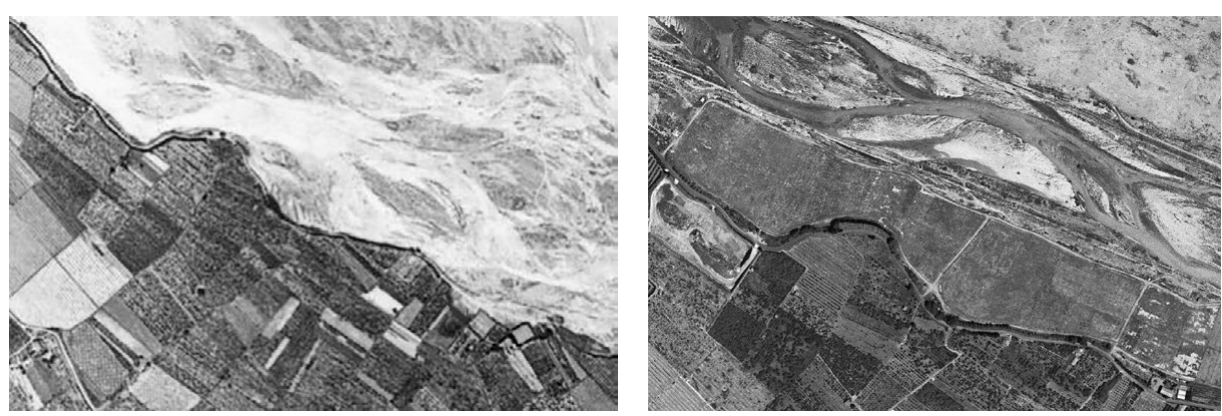

Figura 6. Detalles de la fotografía aérea de 1956 (arriba) y de la ortofoto de 2002 (abajo) correspondientes a la margen meridional (sector de Vinarragell) en las que se aprecia meridianamente el avance de las tierras de cultivo sobre el lecho fluvial, cuyo límite sinuoso viene marcado en la fotografía más antigua por un camino que hemos interpretado como primitivo Camí Vora Riu.

esta franja de tierras, supuestamente ganadas al lecho, es fácilmente reconocible desde la carretera de Almassora a Borriana hasta el mar, su límite se desdibuja un tanto en el último tramo.

Allí, mediante el recurso a la toponimia ${ }^{3}$ se plantea la existencia de otra gola, la más septentrional, que recibiría la denominación de la Gola de Pepito, sector depremido al que sigue hacia el interior otro topónimo, no menos interesante, el de el Fondo, es decir, una antigua gola del delta del Millars individualizada por un sector elevado llamado l'Alter de la Rabosa. No acaban aquí las hipótesis planteadas, puesto que si la última, supone una drástica reducción de la extensión del delta por el norte, también se podría plantear, aunque de forma muy conjetural, un proceso similar en la parte meridional, en los terrenos situados, aproximadamente, entre el Palaciet y el río.

La evolución posterior tanto en la margen septentrional como en la meridional, así como en el propio delta, no ofrecen ninguna duda y, al tiempo, sirven para cimentar las ideas anteriormente expuestas, ya que entre 1956 y 2002, se completa la ocupación de la margen de Almassora, adquiere gran relevancia en la de Borriana (Figura 7) y se completa en los Alters del delta (Figura 5).

Por último, es preciso indicar que las amputaciones más recientes se vinculan con el encauzamiento del río. Desde el puente de Borriana hasta la actual desembocadura, sendas motas construidas por el amontonamiento de aluviones confinan o pretenden confinar el lecho en un cauce enteramente artificial de tan sólo xx metros de anchura (Figura 5). De este modo, se podría decir que únicamente es funcional la gola más meridional o desembocadura propiamente

3. La relación de topónimos empleados nos ha sido facilitada de forma oral por Jesús Ferrando, quien nos remite a los trabajos de Norbert Mesado. 
dicha del Millars. Y se ha utilizado el condicional, porque en alguna ocasión, 1989, las avenidas ya han roto el encorsetamiento de la mota septentrional que, por su naturaleza detrítica, sufre un progresivo adelgazamiento relacionado con las migraciones laterales de los canales entrelazdos típicos de un curso fluvial braided. Circunstancia asumida por Segura (2006: 93) cuando afirma que el encauzamiento no es garantía suficiente para evitar las inundaciones de la parte distal del abanico.

\section{A MODO DE PERSPECTIVA}

Con todo, conviene remarcar que estas modificaciones recientes sufridas por el lecho del Millars pueden considerarse como las más drásticas, puesto que, en poco tiempo, se ha pasado de poco más de 490 ha de superficie ocupada por el lecho, a tan sólo 92 ha en este tramo final que se ha analizado. Cifras que, en definitiva, sirven para ahirmar la idea de que durante este intervalo temporal la actitud o, mejor, las relaciones entre sociedad y río han dejado de tener un sentido horizontal y de integración, para convertirse en una relación vertical y de dominación por parte de la sociedad. Se conocen los inconvenientes del río, cuáles son sus limitaciones y el objetivo es vencerlos, superarlos. La desvinculación es muy grande, el río continúa aportando los recursos hídricos, además, el aluvión nutre de materiales necesarios para la construcción de infraestructuras, se ha convertido en colector de aguas residuales y vertidos de todo tipo e, incluso, en ocasiones, es un espacio al que resulta difícil acceder. Se sientan, con este análisis inicial, las bases para concretar este proceso de artificialización reciente del curso bajo del Millars.

\section{BiBLIOGRAFÍA}

CAVANILles, A.J. (1795): Observaciones sobre la historia natural, geografia, agricultura, poblacion y frutos del Reyno de Valencia, facsímil de la Ed. de la Imprenta Real en Madrid, de Albatros Ediciones, Bibliotheca Valentina, 1 ValĖncia, vol. I, 1985, 236 pp. + 1 mapa.

Domingo PÉRez, C. (1983): La Plana de Castellón: formación de un paisaje agrario mediterráneo, Confederación de Cajas de Ahorro, Castellón, 308 pp.

GARCÍA FERnÁNDEZ, J. (1995): «Los problemas del medio ambiente y la ordenación del territorio», en Medio Ambiente y Ordenación del Territorio, Secretariado de Publicaciones-Universidad de Valladolid, pp. 7-31.

GARCía FERnándeZ, J. (1995): «Planteamiento de problemas generales del medio ambiente», en Medio Ambiente y Desarrollo Rural, Fundación Duques de SoriaUniversidad de Valladolid, Valladolid, pp. 7-34.

GimÉnez Font, P. (2008a): Las transformaciones del paisaje valenciano en el siglo XVIII, Institució Alfons el Magnànim, València, 460 pp. 
GiMÉNEZ FonT, P. (2008b): «Colonización territorial, razón ilustrada y particularidades valencianas en la nueva población de Benadressa (Castelló de la Plana)», en Cuadernos de Geografía, n. ${ }^{\circ}$ 83, pp. 61-80.

Marco Molina, J.A.; Matarredona Coll, E. y Padilla Blanco, A. (1998): «Integración de los estudios del medio físico en la ordenación del territorio: valoración ecológico-paisajística del Río Algar (Altea, Alicante)», en Investigaciones Geográficas, n. ${ }^{\circ}$ 20, pp. 119-140.

Mateu Bellés, J.F. (1989): «Assuts I vores fluvials regades al País Valencià medieval», en Los paisajes del agua, Universidades de Alicante y Valencia, pp. 165-185.

Mateu Bellés, J.F. (1995): «Cavanilles y el oficio ilustrado de viajar», en Las observaciones de Cavanilles doscientos años después, I, València, pp. 15-55.

Segura Beltran, F.S. (1990): Las ramblas valencianas. Algunos aspectos de hidrología, geomorfología y sedimentología. Universitat de València, $229 \mathrm{pp}$.

Segura Beltran, F.S. (2006): «Las inundaciones en la Plana de Castelló», en Cuadernos

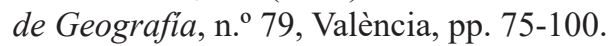

